4

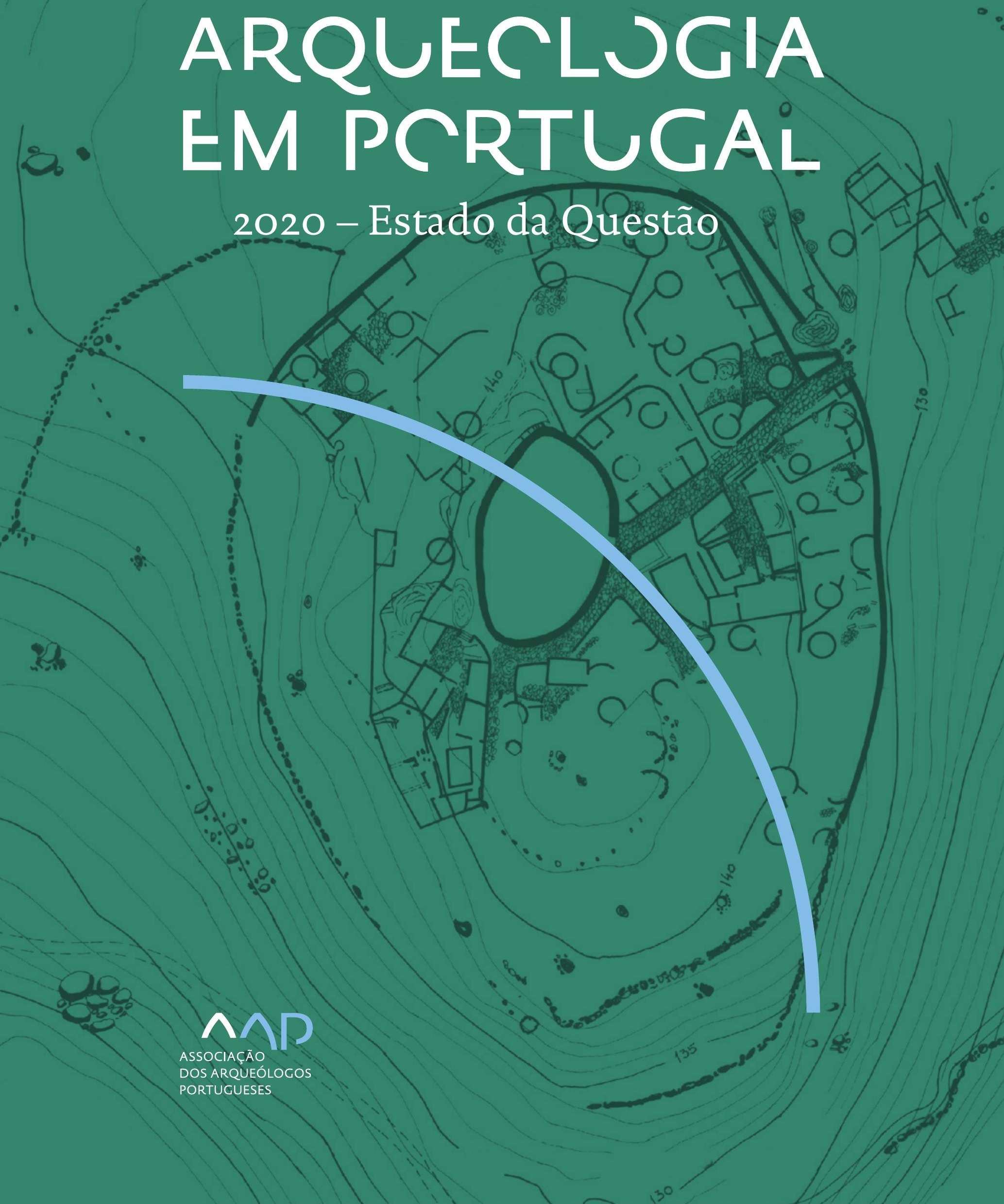


Coordenação editorial: José Morais Arnaud, César Neves e Andrea Martins Design gráfico: Flatland Design

AAP - ISBN: 978-972-9451-89-8

CITCEM - ISBN: 978-989-8970-25-1

Associação dos Arqueólogos Portugueses e CITCEM

Lisboa, 2020

O conteúdo dos artigos é da inteira responsabilidade dos autores. Sendo assim a Associação dos Arqueólogos Portugueses declina qualquer responsabilidade por eventuais equívocos ou questões de ordem ética e legal.

Desenho de capa:

Planta do castro de Monte Mozinho (Museu Municipal de Penafiel).

\section{$\hat{\wedge} \mathrm{P}$}

DOS ARQUEÓLOGOS PORTUGUESES

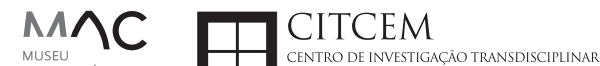
MUSEU
ARQUELLÓGICO
DO CARMO
U.PORTO

FLUP FACULDADE DE LETRAS
UNIVERSIDADE DO PORTO

Apoio

EC para a Ciência 


\section{Índice}

15 Prefácio

José Morais Arnaud

\section{Historiografia e Teoria}

17 Território, comunidade, memória e emoção: a contribuição da história da arqueologia (algumas primeiras e breves reflexões)

Ana Cristina Martins

25 Como descolonizar a arqueologia portuguesa?

Rui Gomes Coelho

41 Arqueologia e Modernidade: uma revisitação pessoal e breve de alguns aspetos da obra homónima de Julian Thomas de 2004

Vítor Oliveira Jorge

57 Dados para a História das Mulheres na Arqueologia portuguesa, dos finais do século XIX aos inícios do século XX: números, nomes e tabelas

Filipa Dimas / Mariana Diniz

73 Retractos da arqueologia portuguesa na imprensa: (in)visibilidades no feminino

Catarina Costeira / Elsa Luís

85 Arqueologia e Arqueólogos no Norte de Portugal Jacinta Bugalhão

101 Vieira Guimarães (1864-1939) e a arqueologia em Tomar: uma abordagem sobre o território e as gentes

João Amendoeira Peixoto / Ana Cristina Martins

115 Os memoráveis? A arqueologia algarvia na imprensa nacional e regional na presente centúria (2001-2019): características, visões do(s) passado(s) e a arqueologia

enquanto marca

Frederico Agosto / João Silva

129 A Evolução da Arqueologia Urbana e a Valorização Patrimonial no Barlavento Algarvio: Os casos de Portimão e Silves

Artur Mateus / Diogo Varandas / Rafael Boavida

\section{Gestão, Valorização e Salvaguarda do Património}

145 O Caderno Reivindicativo e as condições de trabalho em Arqueologia Miguel Rocha / Liliana Matias Carvalho / Regis Barbosa / Mauro Correia / Sara Simões / Jacinta Bugalhão / Sara Brito / Liliana Veríssimo Carvalho / Richard Peace / Pedro Peça / Cézer Santos

155 Os Estudos de Impacte Patrimonial como elemento para uma estratégia sustentável de minimização de impactes no âmbito de reconversões agrícolas Tiago do Pereiro

165 Salvaguarda de Património arqueológico em operações florestais: gestão e sensibilização Filipa Bragança / Gertrudes Zambujo / Sandra Lourenço / Belém Paiva / Carlos Banha / Frederico Tatá Regala / Helena Moura / Jacinta Bugalhão / João Marques / José Correia / Pedro Faria / Samuel Melro

179 Os valores do Património: uma investigação sobre os Sítios Pré-históricos de Arte Rupestre do Vale do Rio Côa e de Siega Verde José Paulo Francisco 
189 Conjugando recursos arqueológicos e naturais para potenciar as visitas ao Geoparque Litoral de Viana do Castelo (Noroeste de Portugal)

Hugo A. Sampaio / Ana M.S. Bettencourt / Susana Marinho / Ricardo Carvalhido

203 Áreas de Potencial Arqueológico na Região do Médio Tejo: Modelo Espacial Preditivo Rita Ferreira Anastácio / Ana Filipa Martins / Luiz Oosterbeek

223 Património Arqueológico e Gestão Territorial: O contributo da Arqueologia para a revisão do PDM de Avis

Ana Cristina Ribeiro

237 A coleção arqueológica do extinto Museu Municipal do Porto - Origens, Percursos e Estudos

Sónia Couto

251 Valpaços - uma nova carta arqueológica

Pedro Pereira / Maria de Fátima Casares Machado

263 Arqueologia na Cidade de Peniche

Adriano Constantino / Luís Rendeiro

273 Arqueologia Urbana: a cidade de Lagos como caso de Estudo Cátia Neto

285 Estratégias de promoção do património cultural subaquático nos Açores. O caso da ilha do Faial

José Luís Neto / José Bettencourt / Luís Borges / Pedro Parreira

297 Carta Arqueológica da Cidade Velha: Uma primeira abordagem

Jaylson Monteiro / Nireide Tavares / Sara da Veiga / Claudino Ramos / Edson Brito /

Carlos Carvalho / Francisco Moreira / Adalberto Tavares

311 Antropologia Virtual: novas metodologias para a análise morfológica e funcional Ricardo Miguel Godinho / Célia Gonçalves

\section{Didáctica da Arqueologia}

327 Como os projetos de Arqueologia podem contribuir para uma comunidade culturalmente mais consciente Alexandra Figueiredo / Claúdio Monteiro / Adolfo Silveira / Ricardo Lopes

337 Educação Patrimonial - Um cidadão esclarecido é um cidadão ativo! Ana Paula Almeida

351 A aproximação da Arqueologia à sala de aula: um caso de estudo no $3^{\circ}$ ciclo do Ensino Básico Luís Serrão Gil

363 Arqueologia 3.o - Pensar e comunicar a Arqueologia para um futuro sustentável Mónica Rolo

377 “Conversa de Arqueólogos" - Divulgar a Arqueologia em tempos de Pandemia Diogo Teixeira Dias

389 Escola Profissional de Arqueologia: desafios e oportunidades Susana Nunes / Dulcineia Pinto / Júlia Silva / Ana Mascarenhas

399 Os Museus de Arqueologia e os Jovens: a oferta educativa para o público adolescente Beatriz Correia Barata / Leonor Medeiros

411 O museu universitário como mediador entre a ciência e a sociedade: o exemplo da secção de arqueologia no Museu de História Natural e da Ciência da Universidade do Porto (MHNC-UP)

Rita Gaspar 
421 Museu de Lanifícios: Real Fábrica de Panos. Atividades no âmbito da Arqueologia Beatriz Correia Barata / Rita Salvado

427 Arqueologia Pública e o caso da localidade da Mata (Torres Novas) Cláudia Manso / Ana Rita Ferreira / Cristiana Ferreira / Vanessa Cardoso Antunes

431 Do sítio arqueológico ao museu: um percurso (também) didático Lídia Fernandes

447 Estão todos convidados para a Festa! E para dançar também... O projecto do Serviço Educativo do Museu Arqueológico do Carmo na $5^{\underline{a}}$ Edição da Festa da Arqueologia Rita Pires dos Santos

459 O “Clã de Carenque”, um projeto didático de arqueologia Eduardo Gonzalez Rocha

469 Mediação cultural: peixe que puxa carroça nas Ruínas Romanas de Troia Inês Vaz Pinto / Ana Patrícia Magalhães / Patrícia Brum / Filipa Santos

481 Didática Arqueológica, experiências do Projeto Mértola Vila Museu Maria de Fátima Palma / Clara Rodrigues / Susana Gómez / Lígia Rafael

\section{Arte Rupestre}

497 Os inventários de arte rupestre em Portugal Mila Simões de Abreu

513 O projeto FIRST-ART - conservação, documentação e gestão das primeiras manifestações de arte rupestre no Sudoeste da Península Ibérica: as grutas do Escoural e Maltravieso Sara Garcês / Hipólito Collado / José Julio García Arranz / Luiz Oosterbeek / António Carlos Silva / Pierluigi Rosina / Hugo Gomes / Anabela Borralheiro Pereira / George Nash / Esmeralda Gomes / Nelson Almeida / Carlos Carpetudo

523 Trabalhos de documentação de arte paleolítica realizados no âmbito do projeto PalæoCôa André Tomás Santos / António Fernando Barbosa / Luís Luís / Marcelo Silvestre / Thierry Aubry

537 Imagens fantasmagóricas, silhuetas elusivas: as figuras humanas na arte do Paleolítico Superior da região do Côa Mário Reis

$55^{1}$ Os motivos zoomórficos representados nas placas de tear de Vila Nova de São Pedro (Azambuja, Portugal) Andrea Martins / César Neves / José M. Arnaud / Mariana Diniz

571 Arte Rupestre do Monte de Góios (Lanhelas, Caminha). Síntese dos resultados dos trabalhos efectuados em 2007-2009 Mário Varela Gomes

599 Gravuras rupestres de barquiformes no Monte de S. Romão, Guimarães, Noroeste de Portugal Daniela Cardoso

613 Círculos segmentados gravados na Bacia do Rio Lima (Noroeste de Portugal): contributos para o seu estudo Diogo Marinho / Ana M.S. Bettencourt / Hugo Aluai Sampaio

631 Equídeos gravados no curso inferior do Rio Mouro, Monção (NW Portugal). Análise preliminar Coutinho, L.M. / Bettencourt, A.M.S / Sampaio, Hugo A.S

645 Paletas na Arte Rupestre do Noroeste de Portugal. Inventário preliminar Bruna Sousa Afonso / Ana M. S. Bettencourt / Hugo A. Sampaio 


\section{Pré-História}

661 O projeto Miño/Minho: balanço de quatro anos de trabalhos arqueológicos Sérgio Monteiro-Rodrigues / João Pedro Cunha-Ribeiro / Eduardo Méndez-Quintas / Carlos Ferreira / Pedro Xavier / José Meireles / Alberto Gomes / Manuel Santonja / Alfredo Pérez-González

677 A ocupação paleolítica da margem esquerda do Baixo Minho: a indústria lítica do sítio de Pedreiras 2 (Monção, Portugal) e a sua integração no contexto regional Carlos Ferreira / João Pedro Cunha-Ribeiro / Sérgio Monteiro-Rodrigues / Eduardo Méndez-Quintas / Pedro Xavier / José Meireles / Alberto Gomes / Manuel Santonja / Alfredo Pérez-González

693 O sítio acheulense do Plistocénico médio da Gruta da Aroeira Joan Daura / Montserrat Sanz / Filipa Rodrigues / Pedro Souto / João Zilhão

703 As sociedades neandertais no Barlavento algarvio: modelos preditivos com recurso aos SIG

Daniela Maio

715 A utilização de quartzo durante o Paleolítico Superior no território dos vales dos rios Vouga e Côa

Cristina Gameiro / Thierry Aubry / Bárbara Costa / Sérgio Gomes / Luís Luís / Carmen Manzano / André Tomás Santos

733 Uma perspetiva diacrónica da ocupação do concheiro do Cabeço da Amoreira (Muge, Portugal) a partir da tecnologia lítica Joana Belmiro / João Cascalheira / Célia Gonçalves

745 Novos dados sobre a Pré-história Antiga no concelho de Palmela. A intervenção arqueológica no sítio do Poceirão I

Michelle Teixeira Santos

757 Problemas em torno de Datas Absolutas Pré-Históricas no Norte do Alentejo Jorge de Oliveira

771 Povoamento pré-histórico nas áreas montanhosas do NO de Portugal: o Abrigo 1 de Vale de Cerdeira Pedro Xavier / José Meireles / Carlos Alves

783 Apreciação do povoamento do Neolítico Inicial na Baixa Bacia do Douro. A Lavra I (Serra da Aboboreira) como caso de estudo Maria de Jesus Sanches

797 O Processo de Neolitização na Plataforma do Mondego: os dados do Sector C do Outeiro dos Castelos de Beijós (Carregal do Sal)

João Carlos de Senna-Martinez / José Manuel Quintã Ventura / Andreia Carvalho / Cíntia Maurício

823 Novos trabalhos na Lapa da Bugalheira (Almonda, Torres Novas) Filipa Rodrigues / Pedro Souto / Artur Ferreira / Alexandre Varanda / Luís Gomes / Helena Gomes / João Zilhão

837 A pedra polida e afeiçoada do sítio do Neolítico médio da Moita do Ourives (Benavente, Portugal)

César Neves

857 Casal do Outeiro (Encarnação, Mafra): novos contributos para o conhecimento do povoamento do Neolítico final na Península de Lisboa.

Cátia Delicado / Carlos Maneira e Costa / Marta Miranda / Ana Catarina Sousa

873 Stresse infantil, morbilidade e mortalidade no sítio arqueológico do Neolítico Final/ Calcolítico ( $4^{\circ}$ e $3^{\circ}$ milénio a.C.) do Monte do Carrascal 2 (Ferreira do Alentejo, Beja) Liliana Matias de Carvalho / Sofia N. Wasterlain 
885 Come together: O Conjunto Megalítico das Motas (Monção, Viana do Castelo) e as expressões Campaniformes do Alto Minho Ana Catarina Basílio / Rui Ramos

899 Trabalhos arqueológicos no sítio Calcolítico da Pedreira do Poio Carla Magalhães / João Muralha / Mário Reis / António Batarda Fernandes

913 O sítio arqueológico de Castanheiro do Vento. Da arquitectura do sítio à arquitectura de um território João Muralha Cardoso

925 Estudo zooarqueológico das faunas do Calcolítico final de Vila Nova de São Pedro (Azambuja, Portugal): Campanhas de 2017 e 2018 Cleia Detry / Ana Catarina Francisco / Mariana Diniz / Andrea Martins / César Neves / José Morais Arnaud

943 As faunas depositadas no Museu Arqueológico do Carmo provenientes de Vila Nova de São Pedro (Azambuja): as campanhas de 1937 a 1967 Ana Catarina Francisco / Cleia Detry / César Neves / Andrea Martins / Mariana Diniz / José Morais Arnaud

959 Análise funcional de material lítico em sílex do castro de Vila Nova de S. Pedro (Azambuja, Portugal): uma primeira abordagem Rafael Lima

971 O recinto da Folha do Ouro 1 (Serpa) no contexto dos recintos de fossos calcolíticos alentejanos

António Carlos Valera / Tiago do Pereiro / Pedro Valério / António M. Monge Soares

\section{Proto-História}

987 Produção de sal marinho na Idade do Bronze do noroeste Português. Alguns dados para uma reflexão

Ana M. S. Bettencourt / Sara Luz / Nuno Oliveira / Pedro P. Simões / Maria Isabel C. Alves / Emílio Abad-Vidal

1001 A estátua-menir do Pedrão ou de São Bartolomeu do Mar (Esposende, noroeste de Portugal) no contexto arqueológico da fachada costeira de entre os rios Neiva e Cávado Ana M. S. Bettencourt / Manuel Santos-Estévez / Pedro Pimenta Simões / Luís Gonçalves

1015 O Castro do Muro (Vandoma/Baltar, Paredes) - notas para uma biografia de ocupação da Idade do Bronze à Idade Média

Maria Antónia D. Silva / Ana M. S. Bettencourt / António Manuel S. P. Silva / Natália Félix

1031 Do Bronze Final à Idade Média - continuidades e hiatos na ocupação de Povoados em Oliveira de Azeméis João Tiago Tavares / Adriaan de Man

1041 As faunas do final da Idade do Bronze no Sul de Portugal: leituras desde o Outeiro do Circo (Beja)

Nelson J. Almeida / Íris Dias / Cleia Detry / Eduardo Porfírio / Miguel Serra

1055 A Espada do Monte das Oliveiras (Serpa) - uma arma do Bronze Pleno do Sudoeste Rui M. G. Monge Soares / Pedro Valério / Mariana Nabais / António M. Monge Soares

1065 São Julião da Branca (Albergaria-a-Velha) - Investigação e valorização de um povoado do Bronze Final

António Manuel S. P. Silva / Paulo A. P. Lemos / Sara Almeida e Silva / Edite Martins de Sá

1083 Do castro de S. João ao Mosteiro de Santa Clara: notícia de uma intervenção arqueológica, em Vila do Conde Rui Pinheiro 
1095 O castro de Ovil (Espinho), um quarto de século de investigação - resultados e questões em aberto

Jorge Fernando Salvador / António Manuel S. P. Silva

1111 O Castro de Salreu (Estarreja), um povoado proto-histórico no litoral do Entre Douro e Vouga

Sara Almeida e Silva / António Manuel S. P. Silva / Paulo A. P. Lemos / Edite Martins de Sá

1127 Castro de Nossa Senhora das Necessidades (Sernancelhe): uma primeira análise artefactual Telma Susana O. Ribeiro

${ }_{1141}$ A cividade de Bagunte. O estado atual da investigação Pedro Brochado de Almeida

1153 Zoomorfos na cerâmica da Idade do Ferro no NW Peninsular: inventário, cronologias e significado Nuno Oliveira / Cristina Seoane

1163 Vasos gregos em Portugal: diferentes maneiras de contar a história do intercâmbio cultural na Idade do Ferro

Daniela Ferreira

1175 Os exotica da necrópole da Idade do Ferro do Olival do Senhor dos Mártires (Alcácer do Sal) no seu contexto regional

Francisco B. Gomes

\section{Antiguidade Clássica e Tardia}

1191 O uso de madeira como combustível no sítio da Quinta de Crestelos (Baixo Sabor): da Idade do Ferro à Romanização Filipe Vaz / João Tereso / Sérgio Simões Pereira / José Sastre / Javier Larrazabal Galarza / Susana Cosme / José António Pereira / Israel Espi

1207 Cultivos de Época Romana no Baixo Sabor: continuidade em tempos de mudança? João Pedro Tereso / Sérgio Simões Pereira / Filipe Santos / Luís Seabra / Filipe Vaz

1221 A casa romana na Hispânia: aplicação dos modelos itálicos nas províncias ibéricas Fernanda Magalhães / Diego Machado / Manuela Martins

1235 As pinturas murais romanas da Rua General Sousa Machado, n. ${ }^{5}$ 1, Chaves José Carvalho

1243 Trás do Castelo (Vale de Mir, Pegarinhos, Alijó) - Uma exploração agrícola romana do Douro

Tony Silvino / Pedro Pereira

1255 A sequência de ocupação no quadrante sudeste de Bracara Augusta: as transformações de uma unidade doméstica Lara Fernandes / Manuela Martins

1263 Os Mosaicos com decoração geométrica e geométrico-vegetalista dos sítios arqueológicos da área do Conuentus Bracaraugustanus. Novas abordagens quanto à conservação, restauro, decoração e datação Maria de Fátima Abraços / Licínia Wrench

1277 “Casa Romana” do Castro de São Domingos (Cristelos, Lousada): Escavação, Estudo e Musealização Paulo André de P. Lemos

1291 A arqueobotânica no Castro de Guifões (Matosinhos, Noroeste de Portugal): O primeiro estudo carpológico

Luís Seabra / Andreia Arezes / Catarina Magalhães / José Varela / João Pedro Tereso 
1305 Um Horreum Augustano na Foz do Douro (Monte do Castelo de Gaia, Vila Nova de Gaia) Rui Ramos

1311 Ponderais romanos na Lusitânia: padrões, formas, materiais e contextos de utilização Diego Barrios Rodríguez

1323 Um almofariz centro-itálico na foz do Mondego

Marco Penajoia

1335 Estruturas romanas de Carnide - Lisboa Luísa Batalha / Mário Monteiro / Guilherme Cardoso

1347 O contexto funerário do sector da "necrópole NO" da Rua das Portas de S. Antão (Lisboa): o espaço, os artefactos, os indivíduos e a sua interconectividade na interpretação do passado Sílvia Loja, José Carlos Quaresma, Nelson Cabaço, Marina Lourenço, Sílvia Casimiro, Rodrigo Banha da Silva, Francisca Alves-Cardoso

${ }_{1361}$ Povoamento em época Romana na Amadora - resultados de um projeto pluridisciplinar Gisela Encarnação / Vanessa Dias

1371 A Arquitectura Residencial em Mirobriga (Santiago do Cacém): contributo a partir de um estudo de caso Filipe Sousa / Catarina Felício

${ }_{1385}$ O fim do ciclo. Saneamento e gestão de resíduos nos edifícios termais de Mirobriga (Santiago do Cacém)

Catarina Felício / Filipe Sousa

1399 Balsa, Topografia e Urbanismo de uma Cidade Portuária Vítor Silva Dias / João Pedro Bernardes / Celso Candeias / Cristina Tété Garcia

1413 No Largo das Mouras Velhas em Faro (2017): novas evidências da necrópole norte de Ossonoba e da sua ocupação medieval Ricardo Costeira da Silva / Paulo Botelho / Fernando Santos / Liliana Nunes

1429 Instrumentos de pesca recuperados numa fábrica de salga em Ossonoba (Faro) Inês Rasteiro / Ricardo Costeira da Silva / Paulo Botelho

1439 A Necrópole Romana do Eirô, Duas Igrejas (Penafiel): intervenção arqueológica de 2016 Laura Sousa / Teresa Soeiro

1457 Ritual, descarte ou afetividade? A presença de Canis lupus familiaris na Necrópole Noroeste de Olisipo (Lisboa)

Beatriz Calapez Santos / Sofia Simões Pereira / Rodrigo Banha da Silva / Sílvia Casimiro / Cleia Detry / Francisca Alves Cardoso

1467 Dinâmicas económicas em Bracara na Antiguidade Tardia Diego Machado / Manuela Martins / Fernanda Magalhães / Natália Botica

1479 Cerâmicas e Vidros da Antiguidade Tardia do Edifício sob a Igreja do Bom Jesus (Vila Nova de Gaia) Joaquim Filipe Ramos

1493 Novos contributos para a topografia histórica de Mértola no período romano e na Antiguidade Tardia Virgílio Lopes

\section{8. Época Medieval}

1511 Cerâmicas islâmicas no Garb setentrional "português": algumas evidências e incógnitas Constança dos Santos / Helena Catarino / Susana Gómez / Maria José Gonçalves / Isabel Inácio / Gonçalo Lopes / Jacinta Bugalhão / Sandra Cavaco / Jaquelina Covaneiro / Isabel Cristina Fernandes / Ana Sofia Gomes 
1525 Contributo para o conhecimento da cosmética islâmica, em Silves, durante a Idade Média Rosa Varela Gomes

1537 Yábura e o seu território - uma análise histórico-arqueológica de Évora entre os séculos VIII-XII José Rui Santos

1547 A encosta sul do Castelo de Palmela - resultados preliminares da escavação arqueológica Luís Filipe Pereira / Michelle Teixeira Santos

1559 A igreja de São Lourenço (Mouraria, Lisboa): um conjunto de silos e de cerâmica medieval islâmica

Andreia Filipa Moreira Rodrigues

1571 O registo material de movimentações populacionais no Médio Tejo, durante os séculos XII-XIII. Dois casos de "sunken featured buildings", nos concelhos de Cartaxo e Torres Novas Marco Liberato / Helena Santos / Nuno Santos

1585 O nordeste transmontano nos alvores da Idade média. Notas para reflexão Ana Maria da Costa Oliveira

1601 Sepulturas escavadas na rocha do Norte de Portugal e do Vale do Douro: primeiros resultados do Projecto SER-NPVD

Mário Jorge Barroca / César Guedes / Andreia Arezes / Ana Maria Oliveira

1619 "Portucalem Castrum Novum" entre o Mediterrâneo e o Atlântico: o estudo dos materiais cerâmicos alto-medievais do arqueossítio da rua de D. Hugo, nํ. 5 (Porto) João Luís Veloso

1627 A Alta Idade Média na fronteira de Lafões: notas preliminares sobre a Arqueologia no Concelho de Vouzela

Manuel Luís Real / Catarina Tente

1641 Um conjunto cerâmico medieval fora de portas: um breve testemunho aveirense Susana Temudo

${ }_{1651}$ Os Lóios do Porto: uma perspetiva integrada no panorama funerário da Baixa Idade Média à Época Moderna em meios urbanos em Portugal

Ana Lema Seabra

1659 O Caminho Português Interior de Santiago como eixo viário na Idade Média Pedro Azevedo

1665 Morfologia Urbana: Um exercício em torno do Castelo de Ourém André Donas-Botto / Jaqueline Pereira

1677 Intervenção arqueológica na Rua Marquês de Pombal/Largo do Espírito Santo (Bucelas, Loures)

Florbela Estêvão / Nathalie Antunes-Ferreira / Dário Ramos Neves / Inês Lisboa

1691 O Cemitério Medieval do Poço do Borratém e a espacialidade funerária na cidade de Lisboa Inês Belém / Vanessa Filipe / Vasco Noronha Vieira / Sónia Ferro / Rodrigo Banha da Silva

1705 Um Espaço Funerário Conventual do séc. XV em Lisboa: o caso do Convento de São Domingos da Cidade Sérgio Pedroso / Sílvia Casimiro / Rodrigo Banha da Silva / Francisca Alves Cardoso

\section{9. Época Moderna e Contemporânea}

1721 Arqueologia Moderna em Portugal: algumas reflexões críticas em torno da quantificação de conjuntos cerâmicos e suas inferências históricas e antropológicas Rodrigo Banha da Silva / André Bargão / Sara da Cruz Ferreira

1733 Faianças de dois contextos entre os finais do século XVI e XVIII do Palácio dos Condes de Penafiel, Lisboa

Martim Lopes / Tomás Mesquita 
1747 Um perfil de consumo do século XVIII na foz do Tejo: O caso do Mercado da Ribeira, Lisboa Sara da Cruz Ferreira / Rodrigo Banha da Silva / André Bargão

1761 Os Cachimbos dos Séculos XVII e XVIII do Palácio Mesquitela e Convento dos Inglesinhos (Lisboa)

Inês Simão / Marina Pinto / João Pimenta / Sara da Cruz Ferreira / André Bargão / Rodrigo Banha da Silva

1775 "Tomar os fumos da erua que chamão em Portugal erua sancta». Estudo de Cachimbos provenientes da Rua do Terreiro do Trigo, Lisboa

Miguel Martins de Sousa / José Pedro Henriques / Vanessa Galiza Filipe

1787 Cachimbos de Barro Caulínitico da Sé da Cidade Velha (República de Cabo Verde)

Rodrigo Banha da Silva / João Pimenta / Clementino Amaro

1801 Algumas considerações sobre espólio não cerâmico recuperado no Largo de Jesus (Lisboa) Carlos Boavida

1815 Adereços de vidro, dos séculos XVI-XVIII, procedentes do antigo Convento de Santana de Lisboa (anéis, braceletes e contas)

Joana Gonçalves / Rosa Varela Gomes / Mário Varela Gomes

1837 Da ostentação, luxo e poder à simplicidade do uso quotidiano: arqueologia e simbologia de joias e adornos da Idade Moderna Portuguesa Jéssica Iglésias

1849 Os amuletos em Portugal - dos objetos às superstições: o coral vermelho Alexandra Vieira

1865 Cerâmicas de Vila Franca de Xira nos séculos XV e XVI Eva Pires

1879 «Não passa por teu o que me pertence». Marcas de individualização associadas a faianças do Convento de Nossa Senhora de Aracoeli, Alcácer do Sal Catarina Parreira / Íris Fragoso / Miguel Martins de Sousa

1891 Cerâmica de Leiria: alguns focos de produção

Jaqueline Pereira / André Donas-Botto

1901 Os Fornos na Rua da Biquinha, em Óbidos Hugo Silva / Filipe Oliveira

1909 A casa de Pêro Fernandes, contador dos contos de D. Manuel I: o sítio arqueológico da Silha do Alferes, Seixal (século XVI) Mariana Nunes Ferreira

1921 O Alto da Vigia (Sintra) e a vigilância e defesa da costa Alexandre Gonçalves / Sandra Santos

1937 O contexto da torre sineira da Igreja de Santa Maria de Loures Paulo Calaveira / Martim Lopes

1949 A Necrópole do Hospital Militar do Castelo de São Jorge e as práticas funerárias na Lisboa de Época Moderna Susana Henriques / Liliana Matias de Carvalho / Ana Amarante / Sofia N. Wasterlain

1963 SAND - Sarilhos Grandes Entre dois Mundos: o adro da Igreja e a Paleobiologia dos ossos humanos recuperados

Paula Alves Pereira / Roger Lee Jesus / Bruno M. Magalhães

1975 Expansão urbana da vila de Cascais no século XVII e XVIII: a intervenção arqueológica na Rua da Vitória no 15 a 17

Tiago Pereira / Vanessa Filipe

1987 Novos dados para o conhecimento do Urbanismo de Faro em época Moderna Ana Rosa 
1995 Um exemplo de Arqueologia Urbana em Alcoutim: o Antigo Edifício dos CTT Marco Fernandes / Marta Dias / Alexandra Gradim / Virgílio Lopes / Susana Gómez Martínez

2007 Palácio dos Ferrazes (Rua das Flores/Rua da Vitória, Porto): a cocheira de Domingos Oliveira Maia

Francisco Raimundo

2021 As muitas vidas de um edifício urbano: História, Arqueologia e Antropologia no antigo Recreatório Paroquial de Penafiel Helena Bernardo / Jorge Sampaio / Marta Borges

2035 O convento de Nossa Senhora da Esperança de Ponta Delgada: o contributo da arqueologia para o conhecimento de um monumento identitário João Gonçalves Araújo / N’Zinga Oliveira

2047 Arqueologia na ilha do Corvo... em busca da capela de Nossa Senhora do Rosário Tânia Manuel Casimiro / José Luís Neto / Luís Borges / Pedro Parreira

2059 Perdidos à vista da Costa. Trabalhos arqueológicos subaquáticos na Barra do Tejo Jorge Freire / José Bettencourt / Augusto Salgado

2071 Arqueologia marítima em Cabo Verde: enquadramento e primeiros resultados do projecto CONCHA

José Bettencourt / Adilson Dias / Carlos Lima / Christelle Chouzenoux / Cristóvão Fonseca / Dúnia Pereira / Gonçalo Lopes / Inês Coelho / Jaylson Monteiro / José Lima / Maria Eugénia Alves / Patrícia Carvalho / Tiago Silva

2085 Trabalhos arqueológicos na Cidade Velha (Ribeira Grande de Santiago, Cabo Verde): reflexões sobre um projecto de investigação e divulgação patrimonial André Teixeira / Jaylson Monteiro / Mariana Mateus / Nireide Tavares / Cristovão Fonseca / Gonçalo C. Lopes / Joana Bento Torres / Dúnia Pereira / André Bargão / Aurélie Mayer / Bruno Zélie / Carlos Lima / Christelle Chouzenoux / Inês Henriques / Inês Pinto Coelho / José Lima / Patrícia Carvalho / Tiago Silva

2103 A antiga fortificação de Quelba / Khor Kalba (E.A.U.). Resultados de quatro campanhas de escavações, problemáticas e perspectivas futuras Rui Carita / Rosa Varela Gomes / Mário Varela Gomes / Kamyar Kamyad

2123 Colónias para homens novos: arqueologia da colonização agrária fascista no noroeste ibérico Xurxo Ayán Vila / José Mạ . Señorán Martín 


\title{
"TOMAR OS FUMOS DA ERUA QUE CHAMÃO EM PORTUGAL ERUA SANCTA». ESTUDO DE CACHIMBOS PROVENIENTES DA RUA DO TERREIRO DO TRIGO, LISBOA
}

\author{
Miguel Martins de Sousa ${ }^{1}$, José Pedro Henriques ${ }^{2}$, Vanessa Galiza Filipe ${ }^{3}$
}

\begin{abstract}
RESUMO
A intervenção arqueológica da Rua do Terreiro do Trigo reporta-se ao ano de 2018 e foi motivada pela intenção camarária de instalar ecopontos subterrâneos em determinadas áreas de Lisboa. Entre o conjunto de cachimbos exumados é possível identificar um numeroso grupo de cachimbos de caulino europeus, cronologicamente inseridos entre os séculos XVII e XVIII, bem como um conjunto peculiar de chibuques de pasta negra e cinzenta de origem desconhecida. Este estudo procura, em primeira instância, apresentar o conjunto de cachimbos da Rua do Terreiro do Trigo, mas também abordar o hábito do consumo de tabaco a partir de fontes interdisciplinares referentes à investigação da Idade Moderna.

Palavras-chave: Cachimbos, Chibuques, Idade Moderna, Lisboa, Hábitos de consumo.
\end{abstract}

\begin{abstract}
In 2018 an archaeological intervention in Rua do Terreiro do Trigo was undertaken by municipal determination for the installation of recycling containers in Lisbon. Amongst the sherds recovered it's possible to identify a great amount of European kaolin smoking pipes fragments dated from the 17th to the 18th centuries and also a set of unusual black and grey earthenware chibouks of unknown origin. Therefore, this approach seeks to report the smoking pipe assemblage recovered in Rua do Terreiro do Trigo and to discuss the study of smoking devices in the Portuguese early modern contexts.
\end{abstract}

Keywords: Smoking pipes, Chibouks, Early modern period, Lisbon, Consuming habits.

\section{INTRODUÇÃO}

O estudo de cachimbos corresponde a um dos campos de investigação mais gratificantes da Arqueologia Moderna, devido à fragilidade e consequente ocorrência frequente destes objetos, permitindo a realização, em condições estratigráficas favoráveis, de datações coerentes de sítios arqueológicos. Em acrescento, os cachimbos consistem em evidências de aspetos quotidianos, nomeadamente ao denunciar o ato de fumar e relacionando-se com trocas de gentes de hábitos e mercancias, particularmente o tabaco. "Tomar os fumos da erua que chamão em
Portugal erua sancta" (ANTT, TSO-IL, proc. 1335: fol. 11) surge pois, em concordância com este hábito, no processo inquisitorial quinhentista de Iria Álvares forra da, então, Capitania da Baía de Todos os Santos, filha de indígenas e acusada de crença gentílica e superstições, assinalando o século das primeiras experiências dos portugueses com o hábito de "tomar os fumos".

O presente estudo insere-se na consequente investigação do espólio decorrente da intervenção arqueológica realizada no âmbito de uma das empreitadas do projeto de instalação de ecopontos subterrâneos na cidade de Lisboa. Esta decorreu na

\footnotetext{
1. NOVA FCSH; miguelmsousa1996@gmail.com

2. IAP-NOVA FCSH / Cota 8o.86 Lda.; jpedro-henriques@gmail.com

3. IAP-NOVA FCSH / Cota 8o.86 Lda.; vanessagfilipe@gmail.com
} 
Rua do Terreiro do Trigo, no dinâmico bairro de Alfama, em área defronte à fachada noroeste do antigo edifício da Alfândega de Lisboa, apresentando as seguintes coordenadas geográficas: $38^{\circ} 42^{\prime} 38.64$ " N de latitude e $9^{\circ} 7^{\prime}$ 41.486" O de longitude.

Procura-se, assim, dar a conhecer o conjunto de cachimbos da Rua do Terreiro do Trigo, relevando previamente elementos históricos e arqueológicos da área intervencionada e envolvente. Em complemento, pretende-se abordar aspetos relacionados com o consumo de tabaco e a utilização de cachimbos em Portugal.

\section{ENQUADRAMENTO HISTÓRICO- -ARQUEOLÓGICO DO ESPAÇO}

A nível histórico, dados acerca deste sítio surgem desde o seu topónimo que pressupõe um local destinado ao abastecimento cerealífero, pelo menos até às profundas mudanças neste âmbito que se iniciam em grande medida no século XVIII, com o advento da industrialização em território nacional (Ferreira, 1995, pp. 143-161). Todavia, devemos alertar que o local da sondagem que apresentamos corresponde ao Terreiro do Trigo existente após o terramoto de 1755 , também denominado como Celeiro Público. Em oposição à antiga estrutura estudada por Francisco Duarte Mangas (2016), localizada a sul da Igreja de Nossa Senhora da Misericórdia, atual Igreja de Nossa Senhora da Conceição Velha, o "novo" Terreiro do Trigo situou-se numa área que corresponde a extenso aterro desenvolvido desde o século XVI (Figura 1) e tem vindo a ser re-descoberto graças a obras de requalificação urbana. Prova disso, para além do trabalho que se apresenta, são as intervenções de Cristina Gonzalez que, através de projetos ocorridos em 2010 para a requalificação do sistema de saneamento "entre a Rua do Cais de Santarém e sensivelmente metade da extensão da Rua do Terreiro do Trigo, incluindo o Largo do Terreiro do Trigo e o início da Travessa de São João da Praça” (2012a, p. 847), a sudoeste do presente sítio, desvendou informações inéditas da Ribeira, "um espaço da cidade de Lisboa que ganha destaque com a chegada da Idade Moderna” (2012b, p. 92). Na mesma perspetiva, a nordeste da área intervencionada no Largo do Chafariz de Dentro, a campanha arqueológica promovida pela renovação do sistema de tratamento de águas revelou a ocorrência de aterros desde o século XVI com o intuito de ganhar espaço ao rio, oferecendo expressiva diacronia de materialidades e estruturas (Silva \& alii, 2012, p. 71).

Surge então, neste meio, o espaço que se pode vislumbrar atualmente, perpendicular à fachada de edifício erguido em parte através de material de construção de troço da muralha fernandina da área do Largo do Chafariz de Dentro (Ibid., p. 73). Da Alfândega interina pode referir-se que através de decreto de 12 de junho de 1756 encontra-se atestado o impulso da sua construção, concluída em 1766, desenvolvendo-se a estrutura em três pisos, onde é ainda possível notar a grande solidez da fachada sul, outrora, para suportar as cargas que eram armazenadas, particularmente "açúcar, tabaco e outras mercadorias volumosas” (Santos, 2014, p. 112).

\subsection{Intervenção Arqueológica}

Entre 17 de setembro e 20 de novembro de 2018 decorreu a intervenção arqueológica da Rua do Terreiro do Trigo, no bairro de Alfama, dirigida por um dos signatários (JPH). Este trabalho foi procedente da determinação camarária de realizar diversas empreitadas de escavação para a instalação de contentores de reciclagem. Nestas circunstâncias, a ação arqueológica aludiu a acompanhamento geral da empreitada e a sondagem com área de $28 \mathrm{~m}^{2}$ e profundidade entre 2,2 e 3,3 m. O processo de escavação adotou o método preconizado por Philip Barker (1989), procurando a remoção dos depósitos num processo inverso ao da sua formação e com aplicação da leitura estratigráfica definida por Edward C. Harris (1991).

Estes trabalhos caraterizam-se por consideráveis movimentações no subsolo e evidentes constrangimentos inerentes aos prazos de execução, levando a limitação ou mesmo interdição de circulação na via pública, para além da consequente destruição efetiva da realidade arqueológica. Todavia, não deixam simultaneamente de nos proporcionar a oportunidade de recolher informações em relação à evolução urbanística do núcleo citadino e das pessoas que o ocuparam.

\subsection{Estratigrafia}

A área da sondagem apresentou uma sucessão estratigráfica relativamente simples e em concordância com intervenções na área envolvente. Nesta em particular, as primeiras unidades estratigráficas reportaram-se a realidades contemporâneas de pavimentação e colocação de infra-estruturas de dre- 
nagens de águas domésticas e pluviais, bem como uma vala de grés que cortou parte da realidade estratigráfica, pelo que nela se observou um mistifório de espólio, cronologicamente balizado entre os séculos XVI e XXI.

Em posição subsequente, surgiram níveis relacionados com a construção do Celeiro Público (1756-1766), notando-se a ocorrência frequente de buracos de poste e níveis de circulação. Seguiram-se depósitos, de onde surgiu a maioria dos fragmentos de cachimbos, relacionados com o abandono e destruição do local em consequência do terramoto de 1755 (Figura 2).

Estratigraficamente a baixo, verificou-se um nível de construção ou remodelação de estrutura indeterminada, mas que pode corresponder a uma das que se verificam no Grande Panorama de Lisboa (à guarda no Museu Nacional do Azulejo) entre o Campo das Cebolas e o Chafariz da Praia, surgindo novamente buracos de poste numerosos e dois pavimentos parcamente preservados. Por fim, o último nível detetado, cronologicamente da primeira metade do século XVII ou anterior, corresponde a unidades heterogéneas aplicadas como regularização da frente ribeirinha tendo em vista a colocação de um pavimento em cerâmica moída bastante compacto. É ainda de mencionar, no mesmo nível estratigráfico, uma estrutura não identificada na iconografia e cartografia coeva (Figura 1), que atravessa a sondagem no sentido norte-sul.

\section{OS CACHIMBOS}

Com vista em analisar o conjunto, efetuou-se a lavagem e individualizaram-se todos os fragmentos dos cachimbos, procedendo às possíveis colagens. Os fragmentos foram depois inventariados e marcados com o devido acrónimo, efetuaram-se desenhos, vetorizações e examinaram-se elementos significativos como as pastas e respetivos ENPs, as marcas de produtor e evidências da produção, utilização e/ ou descarte.

Entre os 472 fragmentos exumados de 34 unidades estratigráficas, correspondentes a um número máximo de 447 indivíduos, é possível verificar uma maioria de cachimbos de caulino, com origem europeia e que, através das marcas de produtor identificadas, se podem reportar desde a segunda metade do século XVII até ao século XVIII (Tabela 1). Porém, registam-se também cachimbos pouco recorrentes na investigação arqueológica nacional, de pasta brunida com coloração negra e cinzenta, que se assemelham aos designados como cachimbos turcos/otomanos (Simpson, 1990) ou, não inferindo qualquer noção geográfica, chibuques (Robinson, 1985) e que sugerem corresponder a produções exógenas.

Ainda que numa primeira abordagem os 12 fragmentos de chibuques parecessem bastante diminutos em relação aos 435 fragmentos de cachimbos de caulino, a contagem do número mínimo de indivíduos (NMI), segundo os preceitos de Clive Orton (1982), identificando-se nos pedúnculos dos cachimbos de caulino e no orifício do fornilho dos chibuques elementos singulares, evidenciou-se que, na diminuta área intervencionada, os $15 \mathrm{NMI}$ de cachimbos de caulino e os 8 NMI de chibuques não eram, afinal, tão dispares (Gráfico 1).

\subsection{Cachimbos de caulino}

Registaram-se cerca de 32 fragmentos de fornilhos de cachimbos de caulino, dos quais seis podemos classificar seguramente como ovóides. Todavia, destes, 17 correspondem a fragmentos de parede e 12 apresentam, para além da parede do fornilho, pedúnculo, observando-se três exemplares completos dos quais um não ostenta qualquer tipo de evidência de exposição ao fogo.

Contabilizaram-se 12 fragmentos de fornilhos com decoração sendo que o motivo denticulado inciso, também designado como anel serrilhado ou somente serrilhado (Pereira, 2003, p. 257; Hissa, 2018, p. 116), na superfície exterior do bordo - técnica utilizada na produção inglesa e holandesa de cachimbos, observou-se em 10 fragmentos. Os restantes dois apresentam decoração moldada na superfície exterior, um baseia-se numa moldura circular onde se insere um busto em relevo orientado para elemento fitomórfico (Figura 3-9), semelhante ao identificado em Évora atribuído a produção bávara do último quartel do século XVII (Lopes; Roque, 2012, p. 207) e a conjunto de sete cachimbos provenientes dos antigos Armazéns Sommer que atualmente correspondem a unidade hoteleira designada como Eurostars Museum onde se encontra o conjunto exposto, sendo indicado como de proveniência inglesa e com cronologia da primeira metade do século XVIII. O outro fragmento com decoração moldada, de menor dimensão, apresenta pequenos bolbos e pode corresponder ao mesmo cachimbo do fragmento anterior. 
No que concerne às marcas de produtor, analisaram-se 10 fragmentos que as apresentam no pedúnculo registando-se ainda três fragmentos com marcas ilegíveis e dois com pedúnculo em spur. Com gravação na parte lateral surgiram dois fragmentos de produção londrina (Figura 3-7, 8), os quais se relacionaram com outros dois sem marcas de produtor que também consideramos ingleses, pois apresentam a base do pedúnculo pontiaguda (spur), como em várias produções britânicas (Atkinson; Oswald, 1969, pp. 56-57). Não obstante, a maior parte das marcas que surgiram reportam-se a produções da primeira metade do século XVIII provenientes de Gouda (Tabela 1), o maior centro produtor de cachimbos holandeses (Meulen, 2003), como se comprova pelo brasão da referida cidade presente em três dos exemplares exumados (Figura 3-3, 5, 6) e que pode funcionar como terminus post quem tendo sido utilizado a partir de 1739-1740, várias vezes encimado por um "S", do holandês Slegt (inferior), que denuncia a baixa qualidade das produções em caulino por oposição a produções mais delicadas (Calado; Pimenta; Silva, 2003, pp. 87-88).

De acordo com o que geralmente se sucede em diversos estudos de cachimbos (Higgins, 2017, p. 6), os 403 fragmentos de hastes superaram largamente o número de fornilhos, correspondendo a $93 \%$ dos fragmentos neste suporte. Contaram-se 15 hastes referentes à secção proximal que podem corresponder a fragmentos de boquilhas, muito embora não seja esta uma afirmação segura, pois a execução destas resultava num corte sem acabamento dificultando a sua distinção face aos 385 fragmentos da secção mesial. Contudo, alguns aspetos como a evidência de afeiçoamento, certas marcas de perfuração dentária e o valor do diâmetro do furo visivelmente mais largo, causado pela saída de matéria-prima, permitiram uma classificação como proximal.

Em relação às secções distais das hastes, facilmente identificadas pelo seu maior diâmetro, optámos por acrescentar aos três fragmentos contabilizados, 11 de fornilhos anteriormente referidos com arranque de haste, obtendo um total de 414 fragmentos com vista a medir o comprimento total do conjunto das hastes. Seguiu-se assim a soma de valores, entre 1,2 e $10,7 \mathrm{~cm}$, pelo que se obteve o comprimento total de $1181,15 \mathrm{~cm}$. Esta metodologia, meramente experimental, deveu-se à tomada de consciência de que a partir do século XVIII as hastes apresentariam de 33,02 a 34,29 cm (segundo Hume, 1991, p. 296) sendo que o valor obtido poderia corresponder a 36 cachimbos. No entanto, as hastes de determinados cachimbos poderiam chegar aos $45,72 \mathrm{~cm}$ (Ibid.) cobrindo, neste caso, 26 destes, apesar de ser necessário aprimorar esta metodologia com mais exemplares completos, em particular recolhidos em intervenções arqueológicas.

De qualquer modo, o facto é que o número de hastes é maior do que o dos fornilhos, até no que concerne ao NMI ( 26 hastes por 15 fornilhos). Torna-se assim evidente a reutilização dos fornilhos mesmo com a haste quebrada, denunciando a utilização por parte de indivíduos com poder de compra inferior e que se relaciona simultaneamente com a fragilidade destes objetos, verificando-se ainda casos onde ocorrem quebras intencionais da haste com vista a permitir um melhor encaixe noutro suporte menos compacto (Caldo; Pimenta; Silva, 2003, pp. 92-93). Em termos cromáticos, é de indicar um fragmento de haste com tonalidade avermelhada ( $10 \mathrm{R} 5 / 8$ ) que mede $3,1 \mathrm{~cm}$ de comprimento, o, $6 \mathrm{~cm}$ de diâmetro e, para além de poder corresponder a contaminações de óxido de ferro, pode também aludir a elemento de produção local ou regional, muito embora mais se assemelhe com os restantes fragmentos de pastas homogéneas, fabricadas a molde, constituídos por argilas de caulino bastante depuradas e com acabamento cuidado do qual resultam superfícies lisas. Ainda assim, cachimbos designados como "de barro vermelho", com pastas de matriz calcária, compostas por concentração acentuada de ENPs quartzosos e micáceos, ocorrem em vários sítios do território nacional (Sousa, 2020, pp. 80-81), caraterizando-se por uma estética artesanal, pois talvez "tencionavam satisfazer uma procura de quem não teria acesso às produções ditas de maior qualidade" (Pimenta; Silva, 2019, p. 256) e recorria a produções com grande probabilidade oriundas de Lisboa (Oliveira, 2019). Por sua vez, analisaram-se 45 hastes com decorações no sentido transversal, registando-se $39 \mathrm{com}$ decorações geométricas, nomeadamente um fragmento com uma linha ondulada (Figura 4-1), dois fragmentos que apresentavam somente linhas denticuladas (Figura 4-3), nove que apresentavam linhas de círculos e 27 que conjugavam estes dois últimos motivos (Figura 4-5, 8), ficando as linhas denticuladas inscritas num espaço delimitado por linhas de círculos. Este motivo decorativo, recorrentemente registado em estudos arqueológicos de cachimbos de caulino, teve o seu maior êxito desde 
o final do século XVII e no decorrer do século XVIII nas oficinas holandesas, muito embora fosse utilizado em produções inglesas e francesas (Pinto; Filipe; Miguel, 2011, p. 44).

Com decoração epigráfica em cartelas são de referir seis hastes, três apresentaram a impressão IN GOUDA (Figura 4-4), largamente utilizada pelos produtores dessa cidade. Um diferente fragmento apresenta parte desta impressão, [...] OUDAS, no entanto é antecedido por VIE[...] (Figura 4-7) que, na falta de marcas existentemente com essa disposição, pode corresponder a B:V:EVEN da oficina de Barend Evers ou van Even que laborou entre 1744 e 1768 (Meulen, 2003, p. 101). Surgiu ainda uma cartela com [...]W[I?] EWE[...] (Figura 4-6), contudo esta encontra-se bastante fragmentada levando à hipotética associação com a oficina de Jan van der Wies que funcionou de 1746 a 1776 (Ibid., p. 102). Já a última haste legível apresentou [...]DE VINKo (Figura 4-2), podendo relacionar-se com a oficina de Jacob of Jan de Vinck e Jan of Jacob de Vinck que fabricaram cachimbos de 1730 a 1764 ou com a oficina de Teunis de Vink que laborou entre 1745 e 1782 (Ibid., pp. 102-103).

\subsection{Chibuques}

Sem paralelo apurado em território nacional ${ }^{4}$ exumaram-se, em bom estado de conservação, 21 fragmentos de fornilhos de chibuques, designados em estudo prévio como "cachimbos de barro negro" (Sousa, 202O, p. 82) devido à tonalidade da sua pasta, com caraterísticas mais artesanais e superfícies brunidas que variam entre a tonalidade cinzenta (5YR 5/1) e negra (5YR 2.5/1), com presença de ENPs quartzosos e micáceos. Da colagem destes cachimbos resultaram 12 fragmentos, respetivamente $8 \mathrm{NMI}$, a que correspondem dois elementos completos (Figura 5-1, 2), cinco canas com arranque de corpo (Figura 5-3, 4, 5, 6,7), três bordos, uma secção proximal ou de encaixe da cana e um fragmento de corpo com arranque da base (Figura 5-8). Os exemplares completos permitiram aferir as seguintes medições: cerca de $1 \mathrm{~cm}$ de diâmetro no furo da cana, até $1,7 \mathrm{~cm}$ de diâmetro no bordo, entre 3,7 e 4,5 cm

\footnotetext{
4. Pelo menos para a cronologia enquadrável, dado que se localizaram objetos semelhantes no Museu de Tavira, provenientes do Convento de Nossa Senhora da Graça de Tavira, interpretados como "cachimbos de haxixe" dos séculos XIV ou XV, provenientes do Reino de Granada (Cavaco; Covaneiro, 2017, pp. 203-204).
}

de comprimento e altura média no fornilho, com a base assente em fundo plano, de $3,5 \mathrm{~cm}$.

No que concerne à decoração, estas peças caraterizam-se pela sua pobre expressividade, em particular comparando com conjuntos tipologicamente semelhantes, mas mais substanciais (Robinson, 1985; Simpson, 1990). Não obstante, verificou-se que seis fragmentos (50\% deste conjunto) apresentavam duas linhas incisas transversalmente na secção proximal da cana do fornilho e eram, assim, idênticos morfologicamente a cachimbos encontrados em Barcelona e aos quais se atribuiu estilo balcânico e cronologia seiscentista/setecentista (Beltrán de Heredia; Miró i Alaix; Soberón Rodríguez, 2012, p. 178). Observou-se ainda um fragmento que ostenta denotado espessamento aplicado na cana (Figura 5-7) e uma parede de fornilho com porção da base que apresenta cinco caneluras verticais na superfície exterior (Figura 5-8), ambos com paralelos em espólio oriundo da ilha de Malta (Wood, 2014, pp. 56-59).

Não é possível para já, atendendo às parcas caraterísticas dos chibuques estudados, omitir uma hipotética importação africana, constatando-se a utilização de tabaco por escravos e forros e principalmente atendendo a produções africanas utilizadas em Cabo Verde (Cardoso; Soares, 2010, p. 200) e ao cachimbo, idêntico aos exemplares estudados, com o acrónimo AZ6-072, "em forma de saco", exumado em Azamor e com cronologia setecentista (Teixeira; Karra; Carvalho, 2016, pp. 182, 189). É pois de realçar que fumar tabaco afigurou-se uma ação prestigiante para a comunidade africana, estando associada a membros da elite no século XVII, como a rainha Nzinga Mbande ou Dona Ana de Sousa, verificada em iconografia coeva (Bassani, 1987), propagandose a prática por comunidades africanas em contacto com o continente americano, onde independentemente de se conhecer previamente o tabaco, várias são as relações culturais que se desenvolvem e propagam (Figueirôa-Rêgo, 2015, pp. 87-88).

\section{ABORDAGEM AO HÁBITO DO CONSUMO DE TABACO EM PORTUGAL}

Lisboa e outros pontos nacionais, em particular no litoral, correspondem a aglomerados populacionais de diversa riqueza multi-cultural, realidade não divergente durante a Idade Moderna. É pois neste período histórico que o consumo de tabaco se consolida gradualmente, muito embora a nicotina não seja a única 
substância psicoativa em cachimbos provenientes de análises arqueológicas (Cardomy \& alii, 2018).

Ian Gately, na sua obra relativamente à história do tabaco, refere que em meados do século XVII o consumo desta espécie torna-se num hábito de grande parte da humanidade, tendo atravessado fronteiras onde nenhum americano ou europeu tinha estado até então, através da sua assimilação por parte das comunidades mercadoras da Rota da Seda que a transmitiram por pontos desérticos e quase inabitados (2001, pp. 91-92). Não obstante, deve-se à ação portuguesa a introdução do tabaco no Império Persa, bem como a sua plantação no continente africano e nas cidades de Goa, Macau, Java e Nagasáqui, pontos estratégicos para a expansão deste produto pelo resto do continente asiático (Goodman, 1993, p. 51), embora existam espécies nativas de Nicotiana na Ásia e na Oceânia (Santos; Bracht; Conceição, 2013, p. 121).

Em relação aos cachimbos, é possível avançar que o consumo de tabaco na metrópole, protagonizado por cachimbos de caulino e doutros suportes, apresentou maior destaque durante o século XVIII, em consideração pelos contextos e marcas de produtor aferidas em cerca de 87 arqueossítios nacionais (Sousa, 2020, p. 64). Ainda assim o tabaco, conhecido pelos europeus possivelmente desde 1492 (Rodríguez Gordillo, 2015, p. 29), que se instalou como panaceia em Portugal no século XVI e que se consolidou como bem económico a partir do século XVII, apresenta um consumo mais recorrente segundo modos que escapam aos aferidos arqueologicamente e inclusive antropologicamente (Carvalho; Wasterlain, 2017), em concreto e entre outros (Figura 6), pela inalação em pó, designadamente através de rapé, método preferível aparentemente até ao final do século XVIII (Ruders, 2002, p. 157) e denunciado no século passado como "um grave problema social”, em referência a consumidoras discretas provenientes do mundo rural dos lugares, então quase despovoados, de Marrocos e Roncão na freguesia de Espírito Santo, concelho de Mértola (Ribeiro, 1969, pp. 235-236).

\section{BIBLIOGRAFIA}

ANTT - Arquivo Nacional da Torre do Tombo, Tribunal do Santo Ofício - Inquisição de Lisboa, Processo de Iria Álvares, proc. 1335 .

ATKINSON, David; OSWALD, Adiran (1969) - London Clay Tobacco Pipes. Londres: The Museum of London.

BARKER, Philip (1989) - Techniques of Archaeological Excavation. Londres: B. T. Batsford.

BASSANI, Ezio (1987) - Un Cappuccino nell'Africa nera del seicento: I disegni dei Manoscritti Araldi del Padre Giovanni Antonio Cavazzi da Montecuccolo. Milão: Associazione Poro (Quaderni Poro; 4).

BELTRÁN DE HEREDIA, Julia; MIRÓ I ALAIX, Núria; SOBERÓN RODRÍGUEZ, Mikel (2012) - Les Pipes de Ceràmica no Caolinítica Trobades a Barcelona: Producció i Comerç als Segles XVII-XIX. Quarhis: Quaderns d'Arqueologia i Historia de la Ciutat de Barcelona. Vol. 7. Barcelona: Museu d'Història de Barcelona, pp. 166-191.

CALADO, Marco; PIMENTA, João; SILVA, Rodrigo Banha da (2003) - Cachimbos de cerâmica provenientes da escavação do Caminho de Ronda no Castelo de São Jorge em Lisboa. Estudos/Património. N. 5. Lisboa: IPPAR, pp. 83-95.

CALDEIRA, Arlindo Manuel (2008) - O Tabaco: percurso de uma "planta medicinal" entre a América e a Europa. In Workshop Plantas Medicinais e Fitoterapêuticas nos Trópicos. Lisboa: Instituto de Investigação Científica Tropical, pp. 1-25.

CARDOSO, João Luís; SOARES, António Manuel Monge (2010) - A estação arqueológica de Salamansa (ilha de São Vicente, República de Cabo Verde). Revista Portuguesa de Arqueologia. Vol. 13. Lisboa: IGESPAR, pp. 167-214.

CARDOMY, Stephen B.; KASSABAUM, Megan C.; HUNT, Ryan K.; PRODANOVICH, Natalie; ELLIOTT, Hope; RUSS, Jon (2018) - Residue analysis of smoking pipe fragments from the Feltus archaeological site, Shoutheastern North America. Journal of Archaeological Science: Reports. Vol. 17, pp. 640-649.

CARVALHO, Liliana M. de; WASTERLAIN, Sofia N. (2017) - A Minha Boca Conta uma História: Abrasão Dentária e a sua Relação com Actividade e Hábitos Pessoais numa Amostra Portuguesa de Época Medieval/Moderna. In Arnaud, J. M.; Martins, A. (eds.), Arqueologia em Portugal/2017-Estado da Questão. Lisboa: Associação dos Arqueólogos Portugueses, pp. 1469-1480.

CAVACO, Sandra; COVANEIRO, Jaquelina (2017) - Evidências das Relações Comerciais do Porto de Tavira através da Cerâmica. In Scientia Antiquitatis. Vol. 1. N.ㄹ 2, pp. 195-218.

FERREIRA, J. A. do C. (1995) - A Dessacralização do Pão: Políticas de Abastecimento no Antigo Regime: do Concelho ao Estado Iluminista. Porto: Campo das Letras. 
FIGUEIRÔA-RÊGO, João de (2015) - «Escravos do fumo». Notas sobre a escravatura no contexto tabaqueiro: Bahia, Costa da Mina e Angola. In Lúxan, S. de; Figueirôa-Rêgo, J. de; Sanz Rozalén, V. (eds.), Tabaco e Escravos nos Impérios Ibéricos. Lisboa: CHAM (Estudos e Documentos; 24), pp. 87-108.

GATELY, Iain (2001) - Tobacco. A Cultural History of How an Exotic Plant Seduced Civilization. Nova Iorque: Grove Press.

GONZALEZ, Cristina (2012a) - "Majólicas Italianas do Terreiro do Trigo (Lisboa)”. In Teixeira, A.; Bettencourt, J. (eds.), Velhos e Novos Mundos. Estudos de Arqueologia Moderna. Vol. 2. Lisboa: CHAM (ArqueoArte; 1), pp. 847-854.

GONZALEZ, Cristina (2012b) - Os Novos Espaços da Cidade Moderna. Uma Aproximação à Ribeira de Lisboa através de uma intervenção no Largo do Terreiro do Trigo. In Teixeira, A.; Bettencourt, J. (eds.), Velhos e Novos Mundos. Estudos de Arqueologia Moderna. Vol. 1. Lisboa: CHAM (ArqueoArte; 1), pp. 85-94.

GOODMAN, Jordan (1993) - Tobacco in History. The cultures of dependence. Londres e Nova Iorque: Routledge.

HARRIS, Edward C. (1991) - Principios de Estratigrafia Arqueológica. Barcelona: Editorial Crítica.

HIGGINS, David (2017) - Guidelines for the Recovery and Processing of Clay Tobacco Pipes from Archaeological Projects. Liverpool: Historic England.

HISSA, Sarah de Barros Viana (2018) - O Petyn no cachimbo branco: arqueologia e fumo nos séculos XVII ao XIX. Rio de Janeiro: Tese do Programa de Pós-Graduação em Arqueologia do Museu Nacional, UFRJ.

HUME, Ivor Noël (1991) - A Guide to Artifacts of Colonial America. Nova Iorque: Vintage Books/A Division of Random House, Inc.

LOPES, Gonçalo; ROQUE, Conceição (2012) - A intimidade palaciana no século XVII: objectos provenientes de um esgoto do Paço dos Lobos da Gama (Évora). In Teixeira, A; Bettencourt, J. (eds.), Velhos e Novos Mundos. Estudos de Arqueologia Moderna. Vol. 1. Lisboa: CHAM (ArqueoArte; 1), pp. 201-208.

MANGAS, Francisco Duarte Ferreira (2016) - Segurar a Fome: O Terreiro do Trigo de Lisboa no século XVI. Lisboa: Dissertação de Mestrado em História, especialização História da Época Moderna e dos Descobrimentos apresentada à FCSH-UNL.

MEULEN, J. van der (2003) - Goudse pijpenmakers en hun merken. Leiden: Pijpelogische Kring Nederland.

MUNSELL (1994) - Munsell Soil Color Charts. New Widson, NI: Kollmorgen Instruments - Macbeth Division.
OLIVEIRA, Filipe Santos (2019) - Produção de Cachimbos de Barro na Rua Damasceno Monteiro (Olarias de São Gens), Lisboa - Um Contributo para o seu Estudo. Apontamentos de Arqueologia e Património. Vol. 13. Lisboa: ERA Arqueologia / Núcleo de Investigação Arqueológica - NIA, pp. 67-74.

ORTON, Clive (1982) - Mathematics in Archaeology. Cambridge: Cambridge University Press.

PEREIRA, António Luis (2003) - Cachimbos cerâmicos do século XVII da Casa do Infante (Porto). In Actas das 3..$^{-}$ Jornadas de Cerâmica Medieval e Pós-Medieval. Métodos e Resultados para o seu Estudo. Tondela: CMT, pp. 253-269.

PIMENTA, João; SILVA, Rodrigo Banha da (2019) - Cachimbos de cerâmica provenientes da escavação do Centro de Saúde de Alhandra. Cira-Arqueologia. N.7 7. Vila Franca de Xira: CMVFX-CEAX, pp. 252-258.

PINTO, Marina; FILIPE, Iola; MIGUEL, Lúcia (2011) - Os Cachimbos de Caulino Provenientes do Mercado da Ribeira: Contributo para a História Sócio-Económica da Lisboa Moderna. Apontamentos de Arqueologia e Património. Vol. 7. Lisboa: ERA - Arqueologia / Núcleo de Investigação Arqueológica - NIA, pp. 41-48.

RIBEIRO, Margarida (1969) - Mulheres Fumadoras. In Trabalhos de Antropologia e Etnologia. Vol. XXI. Porto: Instituto de Antropologia «Dr. Mendes Corrêa» - Faculdade de Ciências, pp. 231-242.

ROBINSON, Rebecca C. W. (1985) - Tobacco Pipes of Corinth and of the Athenian Agora. In Hesperia: the Journal of the American School of Classical Studies at Athens. Vol. 54. N.. 2, pp. 149-203.

RODRÍGUEZ GORDILLO, José Manuel (2015) - El descubrimiento y abrigo del tabaco (1492-170o). In Lúxan, S. de; Figueirôa-Rêgo, J. de; Sanz Rozalén, V. (eds.), Tabaco e Escravos nos Impérios Ibéricos. Lisboa: CHAM (Estudos e Documentos; 24), pp. 29-40.

RUDERS, Carl Israel (2002) - Viagem em Portugal 1798-1802. Vols. 1-2. Lisboa: Biblioteca Nacional.

SANTOS, Maria Helena Ribeiro dos (2016) - A Praça do Comércio e os planos para a Renovação da Lisboa baixa. In FARIA, M. F. de (coord.), Do Terreiro do Paço à Praça do Comércio - História de um Espaço Urbano. Lisboa: INCM, pp. 111-134.

SANTOS, Christian Fausto Moraes dos; BRACHT, Fabiano; CONCEIÇÃO, Gisele Cristina da (2013) - Esta que "é uma das delícias, e mimos desta terra...”: o uso indígena do tabaco (N.rustica e N.tabacum) nos relatos de cronistas, viajantes e filósofos naturais dos séculos XVI e XVII. Topoli. Vol. 14. N. ${ }^{2}$, , pp. 119-131. 
SILVA, Rodrigo Banha da; MIRANDA, Pedro; VIEIRA, Vasco Noronha; VICENTE, António Moreira; LOPES, Gonçalo C.; NOZES, Cristina (2012) - Largo do Chafariz de Dentro: Alfama em Época Moderna. In Teixeira, A.; Bettencourt, J. (eds.), Velhos e Novos Mundos. Estudos de Arqueologia Moderna. Vol. 1. Lisboa: CHAM (ArqueoArte; 1), pp. 71-84.

SIMPSON, St John (1990) - A brief introduction to Ottoman clay pipes. Society for Clay Pipe Research Newsletter. N. ${ }^{27}$, pp. 6-10.

SOUSA, Miguel Martins de (2020) - As Evidências dos Estados Alterados de Consciência no Registo Arqueológico da Idade Moderna em Portugal. Lisboa: Dissertação de Mestrado em Arqueologia apresentada à FCSH-UNL.
TEIXEIRA, André; KARRA, Azzeddine; CARVALHO, Patrícia (2016) - Le quotidien de la ville d'Azemmourà l'époque moderne: étude des contextes archéologiques. Arqueologia Medieval. N.ำ 13. Porto: Edições Afrontamento, pp. 171-192.

WOOD, John (2014) - Tobacco Pipes from Dockyard Creek, Birgu Malta. In Higgins, D. (ed.), Journal of Clay Pipe Research. Vol. 3. Wallasey: SCPR, pp: 53-64.
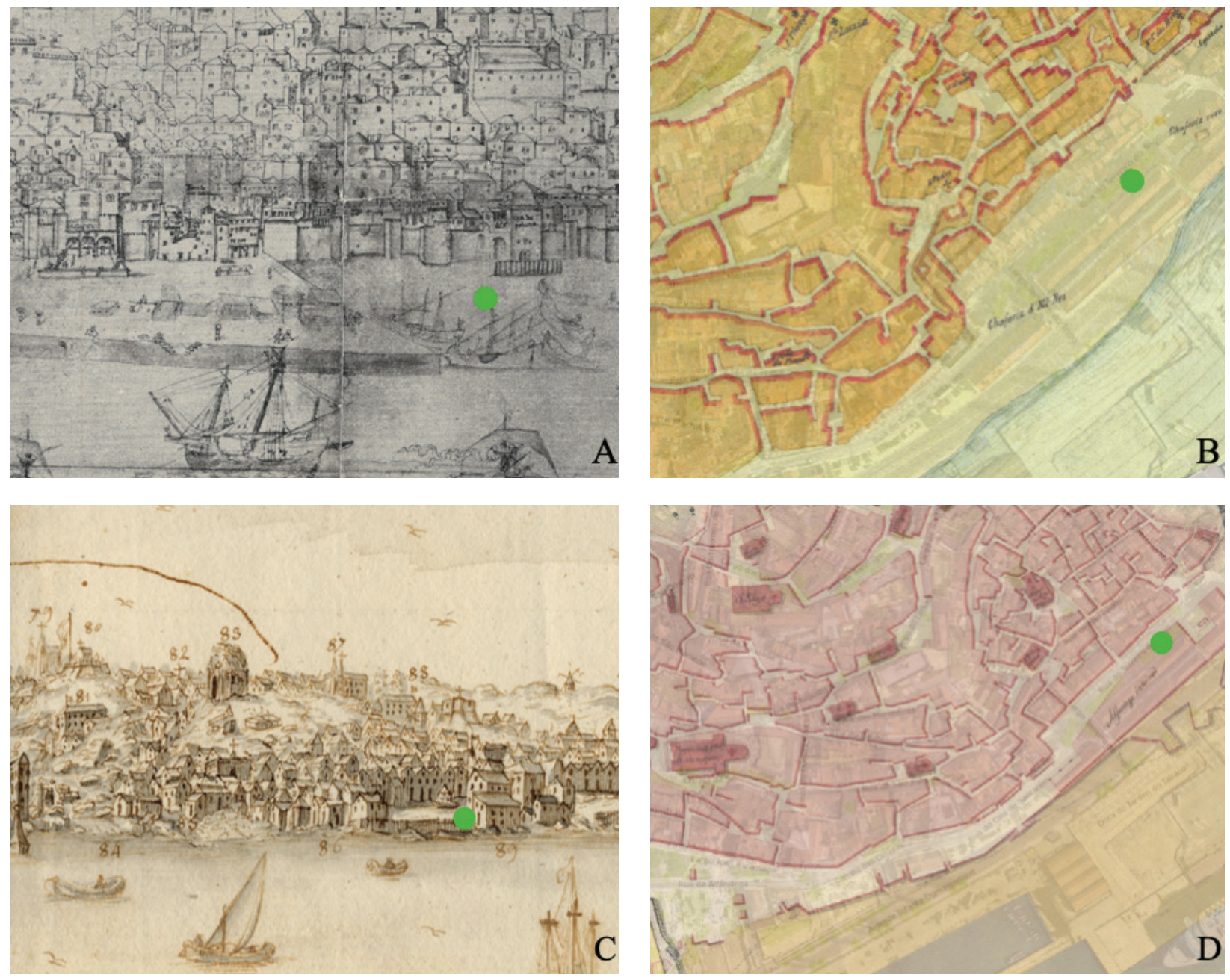

Figura 1 - Localização do sítio escavado em iconografia e sobreposições cartográficas (Fonte: Lisboa Interactiva). A: Vista de Lisboa de anónimo, c. 1570-1580 (Leiden University Library: 29-15-7831-110/30aq). B: Planta de Lisboa de João Nunes Tinoco, 1650 (BNP: cc-1081-a). C: Vista de Lisboa de Bernardo Caula, 1763 (BNP: d-177-r). D: Planta de projeto de Lisboa de Eugénio Santos e Carvalho e Carlos Mardel, 1758 [cópia datada de 1947] (CML: MC.GRA.35). 

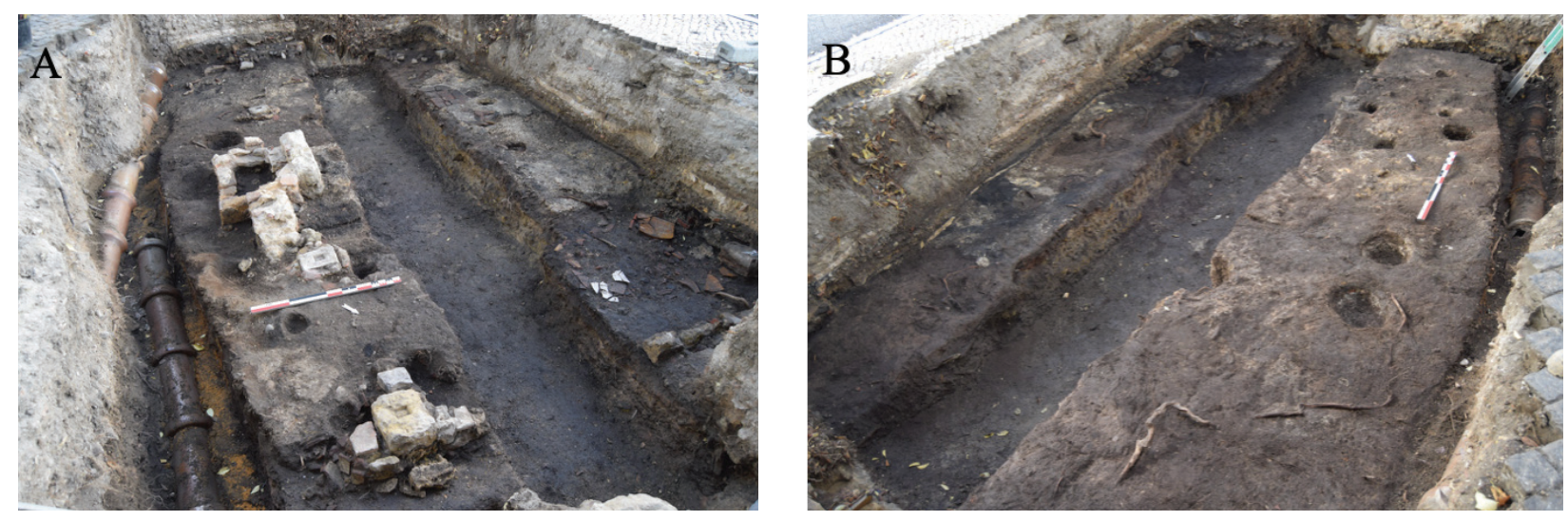

Figura 2 - Registos fotográficos do sítio escavado. A: Vista geral dos níveis de destruição de 1755. B: Vista geral dos níveis de (re-/)construção antes de 1755. Autor: J. P. Henriques.

\begin{tabular}{|c|c|c|c|c|c|c|}
\hline $\begin{array}{c}\text { N. }{ }^{\circ} \text { de } \\
\text { Inventário }\end{array}$ & U.E. & $\begin{array}{l}\text { N. }{ }^{\circ} \text { de } \\
\text { Fragmentos }\end{array}$ & $\begin{array}{l}\text { Marca de } \\
\text { Produtor }\end{array}$ & $\begin{array}{l}\text { Produtor } \\
\text { Atribuído }\end{array}$ & Cronologia & $\begin{array}{l}\text { Local de } \\
\text { Produção }\end{array}$ \\
\hline RTT'18.76 & $\begin{array}{c}{[041-} \\
054]\end{array}$ & 1 & $\begin{array}{c}64 \text { coroado }+ \\
\text { Brasão de Gouda }\end{array}$ & Andries de Vries & $\begin{array}{c}\text { c. } \\
1739 / 40-1755\end{array}$ & Gouda \\
\hline RTT'18.82 & {$[042]$} & 1 & HK coroado & Hendrick Kwast & c. $1719-1749$ & Gouda \\
\hline RTT'18.163 & {$[049]$} & 1 & $\begin{array}{l}\text { Homem a fumar } \\
\text { um cachimbo } \\
\text { numa carroça } \\
\text { (Man in Sjees, } \\
\text { Kar) }\end{array}$ & $\begin{array}{l}\text { Dominicus van } \\
\text { Klaveren/Willem } \\
\text { Hendricksz van } \\
\text { Boksel/Jan van } \\
\text { der Werf }\end{array}$ & $\begin{array}{l}\text { c. } 1733-1740 / \\
\text { c. } 1740-1749 / \\
\text { c. } 1749-1767\end{array}$ & Gouda \\
\hline $\begin{array}{c}\text { RTT'18.191 } \\
/ \\
\text { RTT'18.252 }\end{array}$ & $\begin{array}{c}{[050] /} \\
{[054]}\end{array}$ & 2 & B coroado & $\begin{array}{c}\text { Jan Overwesel/ } \\
\text { Bastiaan } \\
\text { Overwesel }\end{array}$ & $\begin{array}{l}\text { c. } 1730-1746 / \\
\text { c. } 1737-1770\end{array}$ & Gouda \\
\hline RTT'18.216 & {$[050]$} & 1 & $\begin{array}{c}\text { Cesto de fruta } \\
\text { (Fruitben) }+ \\
\text { Brasão de Gouda }\end{array}$ & Jan Nieuwveld & $\begin{array}{c}\text { c. } \\
1739 / 40-1789\end{array}$ & Gouda \\
\hline RTT'18.256 & {$[040]$} & 1 & $\begin{array}{c}\text { L coroado + } \\
\text { Brasão de Gouda }\end{array}$ & $\begin{array}{l}\text { Cornelis de } \\
\text { Licht/Jacob de } \\
\text { Licht }\end{array}$ & $\begin{array}{c}\text { c. } \\
1739 / 40-1745 / \\
\text { c. } 1745-1753\end{array}$ & Gouda \\
\hline RTT'18.361 & {$[075]$} & 1 & $\begin{array}{c}\text { Mão a escrever } \\
\text { (Schrijvende hand) }\end{array}$ & $\begin{array}{l}\text { Hage Jaspersz } \\
\text { van Kint }\end{array}$ & c. $1714-1759$ & Gouda \\
\hline RTT'18.411 & - & 1 & F S & $\begin{array}{c}\text { Ferdinando } \\
\text { Smith/Francis } \\
\text { Saywell/Francis } \\
\text { Stray }\end{array}$ & c. $1642-1732$ & Londres \\
\hline RTT'18.423 & {$[052]$} & 1 & I R & $\begin{array}{c}\text { Joseph Rande/ } \\
\text { John Roome/ } \\
\text { John Reynolds/ } \\
\text { James Roome }\end{array}$ & c. $1667-1730$ & Londres \\
\hline
\end{tabular}

Tabela 1 - Estudo das marcas de produtor dos fornilhos de cachimbos de caulino. 


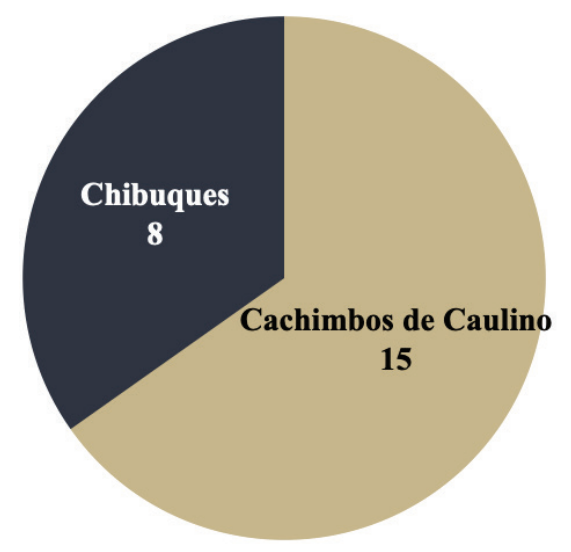

Gráfico 1 - Variação de NMI de cachimbos da Rua do Terreiro do Trigo, Lisboa por tipologia de cachimbo.
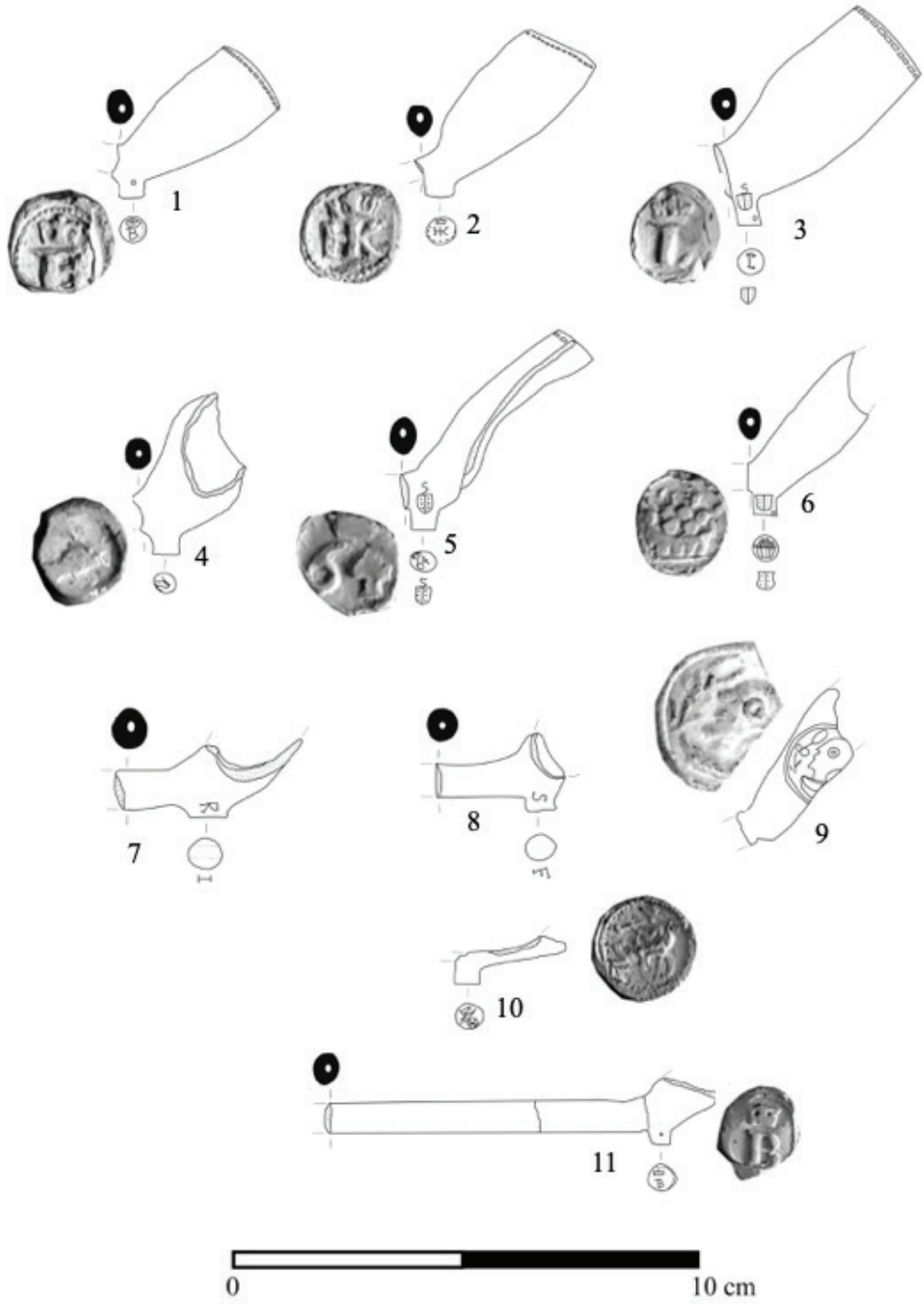

Figura 3-Fornilhos de cachimbos de caulino decorados e com marcas de produtor. 1: RTT'18.252. 2: RTT'18.82. 3: RTT'18.256. 4: RTT'18.361. 5: RTT'18.76. 6: RTT'18.216. 7: RTT'18.423. 8: RTT'18.411. 9: RTT'18.435. 10: RTT'18.163.11: RTT'18.191. Autor: M. M. de Sousa. 
1

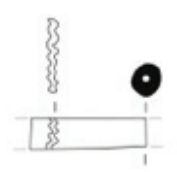

3<smiles>C#CC1CC1</smiles>

5

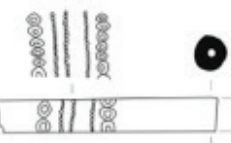

2

(1)
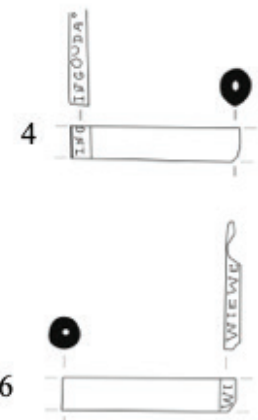

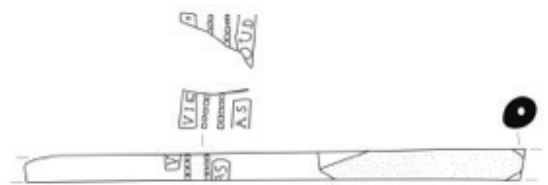

8

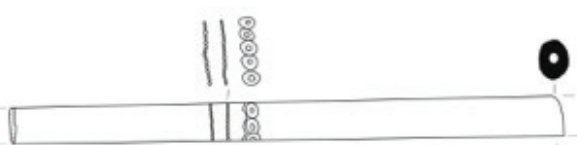

0

Figura 4 - Hastes decoradas de cachimbos de caulino. 1: RTT'18.4. 2: RTT'18.291. 3: RTT'18.5. 4: RTT'18.332. 5 RTT'18.6. 6: RTT'18.165. 7: RTT'18.255. 8: RTT'18.140. Autor: M. M. de Sousa.
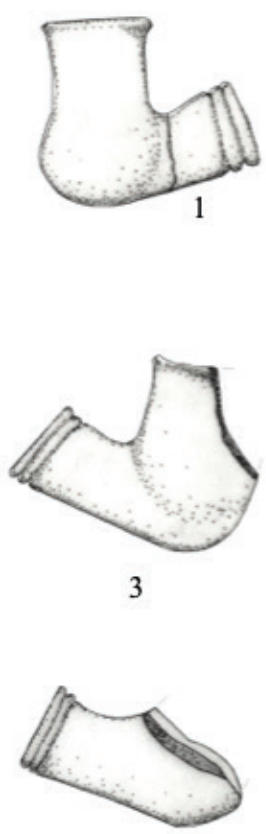

5
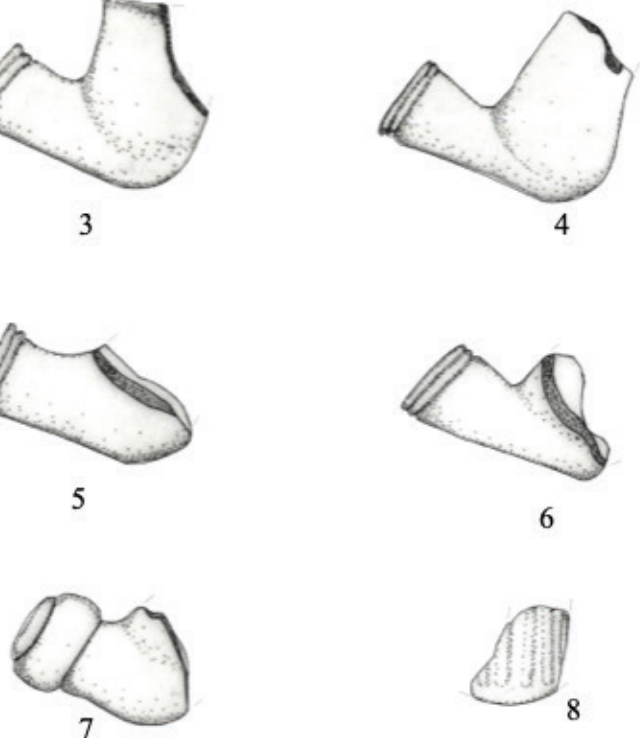

6

8
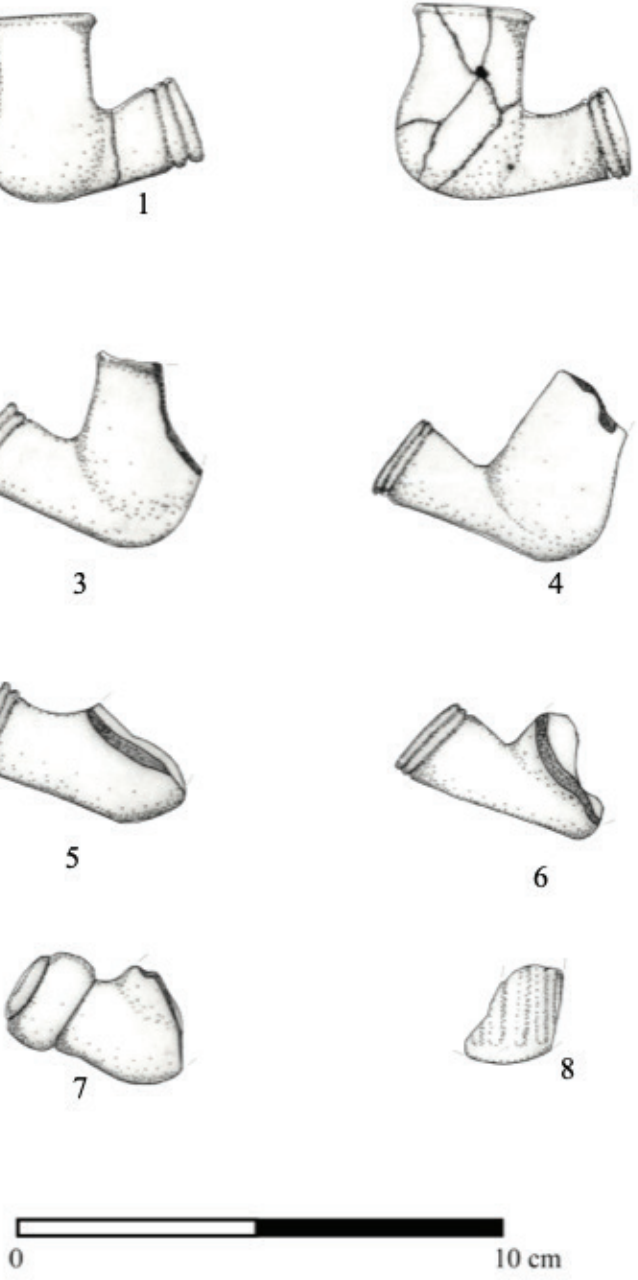

Figura 5-Fornilhos de chibuques.1: RTT'18.441. 2: RTT'18.437. 3: RTT'18.440.4: RTT'18.442. 5: RTT'18.443. 6: RTT'18.447. 7: RTT'18.436. 8: RTT'18.444. Autor: M. M. de Sousa. 

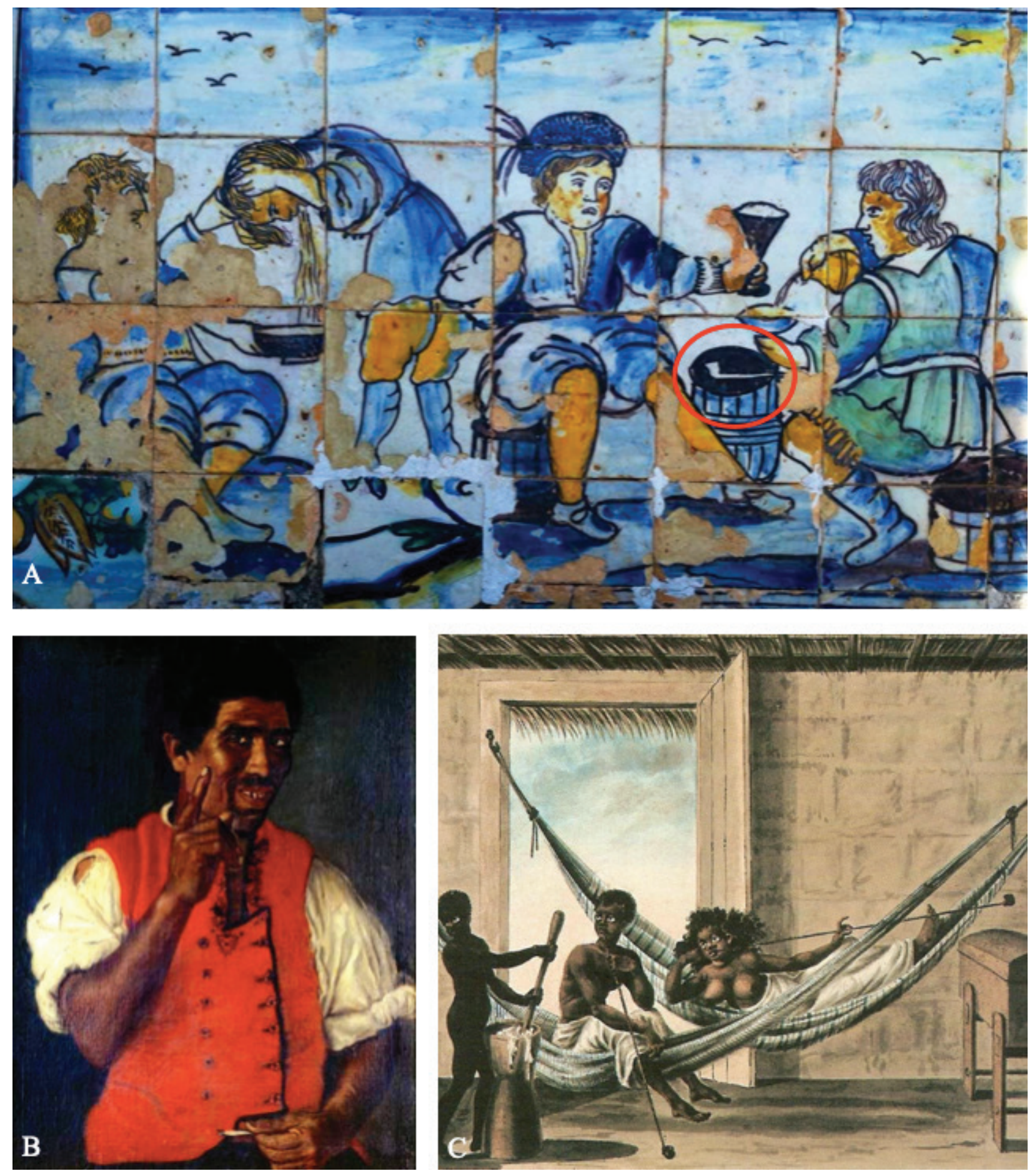

Figura 6 - Iconografia relacionada com o hábito de fumar. A: Pormenor de painel de azulejos, século XVII (Palácio dos Marqueses de Fronteira). B: “Retrato de Negro” por Morgado de Setúbal, século XVIII (MNAA: 33987 TC). C: Pormenor de “Interior de uma casa do baixo povo" por anónimo, c. 1820 (Fonte: Hissa, 2018, p. 39). 



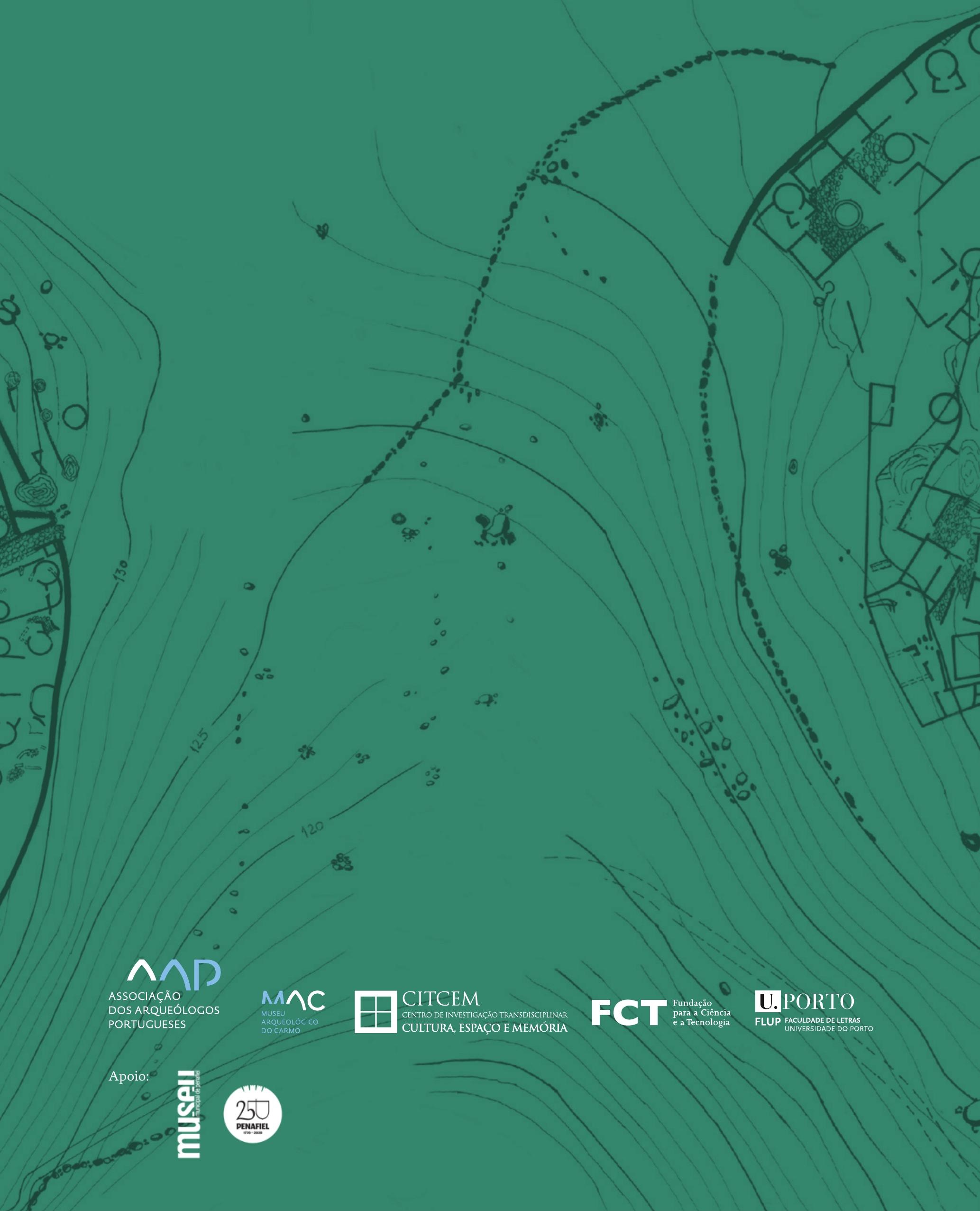

